\section{Functional assessment of temperature- gated ion-channel activity using a real-time PCR machine}

\author{
Derek S. Reubish, Daniel E. Emerling, Jeff DeFalco, Daniel Steiger, \\ Cheryl L. Victoria, and Fabien Vincent \\ In Vitro Pharmacology Department, Evotec, South San Francisco, CA, USA
}

BioTechniques 47:iii-ix (BioTechniques for Preclinical Development September 2009) doi 10.2144/000113198 Keywords: Real-time PCR; temperature; heat; cold; ion channel; assay; TRP channel; thermosensor

Supplementary material for this article is available at www.BioTechniques.com/article/113198.

The functional activity of a number of ion channels is highly sensitive to large changes in temperature. Foremost among these are the thermosensing TRP channels which include cold- (TRPM8, TRPA1), warmth- (TRPV3, TRPV4), and heat-sensing (TRPV1, TRPV2) members. TRPV1, also known as the vanilloid receptor (VR1), is activated by ligands such as capsaicin, acidic $\mathrm{pH}$, and heat (an increase in temperature to $\sim 42^{\circ} \mathrm{C}$ will lead to channel opening). Screening against the thermal gating of TRPV1 is generally performed using perfusion systems or water baths for temperature control, in conjunction with electrophysiology or $\mathrm{Ca}^{2+}$ influx readouts for direct functional assessment. These approaches are very useful, but have limited throughput or minimal thermo-temporal control. A standard realtime PCR machine with standard microplates allowed us to combine fluorescent $\mathrm{Ca}^{2+}$ detection with precise temperature manipulation to develop a homogeneous $\left(Z^{\prime}=0.53\right)$, cell-based assay that uses temperature as the agonist. A temperature response curve of TRPV1 was obtained, which provided a $\mathrm{T}_{50}$ of $46.1^{\circ} \mathrm{C}$, and $\mathrm{IC}_{50}$ values against heat agonism were determined for known TRPV1 antagonists. Furthermore, we expanded this approach to a cold-activated ion channel, TRPM8. We developed and validated an analytical technique with broad applications for the study and screening of temperature-gated ion channels.

\section{Introduction}

Temperature detection and regulation are critical components of various homeostatic and disease-related processes (e.g., thermal adaptation, fever response, inflammation, etc.). Temperature-induced changes in ion channel conductance are one method by which biological systems receive and subsequently quantify thermal information. The quantitative measure of temperature's effect on a given channel is described by the notation $\mathrm{Q}_{10}$, which denotes the fold change in conductance over a span of ten degrees Celsius. Specifically, large temperature effects $\left(\mathrm{Q}_{10}>4\right)$ have been documented for a number of ion channels such as the Shaker
$\left(\mathrm{K}^{+}\right)$, ClC-0 $(\mathrm{Cl}), \mathrm{L}-\mathrm{type}\left(\mathrm{Ca}^{2+}\right)$, and transient receptor potential (TRP) $\left(\mathrm{Ca}^{2+}\right)$ channels (1-5). Perhaps most notable among these is a set of TRP family members shown to be involved directly in thermal sensation with cold-(TRPM8, TRPA1), warmth- (TRPV3, TRPV4), and heat-sensing(TRPV1, TRPV2) members (6-12). Additional members of this family (TRPM2, TRPM4, and TRPM5) were also recently shown to be temperature sensitive (13).

TRPV1 is a well-described cation channel found in nociceptive neurons and present in both $\mathrm{C}$ and $\mathrm{A} \delta$ fibers, as well as in other neural and non-neural tissues (14). Transgenic mice lacking the TRPV1 gene do not develop inflammatory-mediated hyper- algesia, and profiling of TRPV1 antagonists in multiple preclinical animal models of pain strongly suggests this ion channel plays an important role in pain transmission. At the molecular level, TRPV1 responds to a variety of stimuli including low $\mathrm{pH}$, heat $\left(>42^{\circ} \mathrm{C}\right)$, capsaicin, and endogenous ligands such as anandamide (14). This multiplicity of agonists coupled with TRPV1's importance to pain states suggests that TRPV1 may integrate several extracellular signals of inflammatory and neuropathic pain, thus making TRPV1 an attractive target for the development of novel analgesics. As low $\mathrm{pH}$ and the presence of inflammatory mediators results in a decrease in TRPV1 gating temperature (15), temperature is a physiologically relevant stimulus for the discovery and development of TRPV1 antagonists as potential drugs (14).

TRPM8 is a member of the long or melastatin family of TRP channels and was originally identified as an up-regulated transcript in a prostate cancer cell line (16). It is expressed primarily in trigeminal and dorsal root ganglia in both $\mathrm{A}$ and $\mathrm{C}$ fibers, almost exclusively from TRPV1- and TRPA1-expressing neurons (17). TRPM8 is gated by menthol, icilin, and innocuous cold $\left(18-25^{\circ} \mathrm{C} ; \mathrm{Q}_{10}=24\right)$. Recent results from studies of TRPM8-deficient mice indicate that TRPM8 is necessary for proper cold detection and cold-induced analgesia, and is at least partly responsible for mediating cold allodynia in neuropathic pain states (18). Thus, it appears that TRPM8 could be a pharmacological target for indications involving cold hyperalgesia or allodynia.

Current TRP channel high-throughput screening (HTS) assays are constructed around the use of either small-molecule agonists or other easily applicable stimuli [e.g., capsaicin or protons (low $\mathrm{pH}$ ) for TRPV1] to gate the channel and induce $\mathrm{Ca}^{2+}$ influx into cells. In these assays, cells were first loaded with fluorescent $\mathrm{Ca}^{2+}$-sensitive dyes followed by treatment with test compounds (antagonists). Cells were then exposed to an agonist and $\mathrm{Ca}^{2+}$ influx was assessed by measuring changes in intracellular fluorescence with platforms such as Flexstation or FLIPR (Molecular Devices, Sunnyvale, CA, USA). Interestingly, to the best of our knowledge, there have been no published reports of microplatebased assays using continuous temperature changes to trigger TRP channel opening. However, the induction of stepwise, temperature-mediated channel activation using buffers of differing temperature has been reported $(19,20)$. While electrophysiology is another technology that can be used to screen compounds using capsaicin and low $\mathrm{pH}$, it has a much lower throughput when 
A
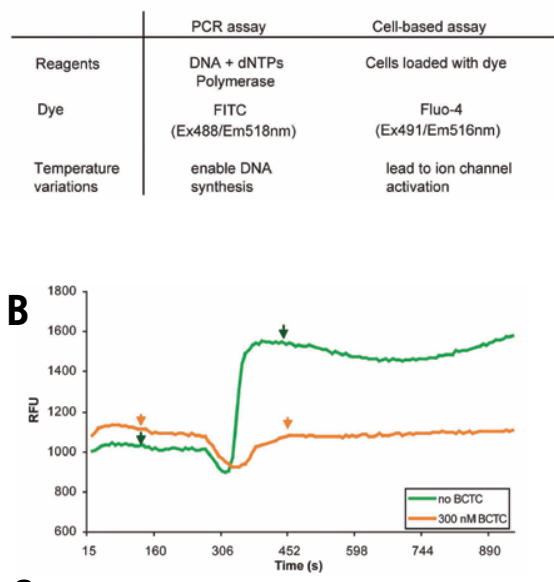

C

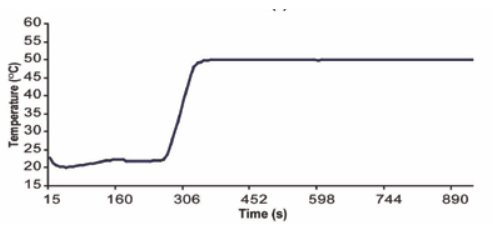

Figure 1. Heat-gated $\mathrm{Ca}^{2+}$ influx in hTRPV1 expressing cells. (A) Assay principle. The temperature assay requires two components to be exchanged (DNA for cells and FITC for Fluo4) for the real-time PCR machine to provide a cell-based assay where channel activation is controlled by temperature and monitored by fluorescence. (B) Fluorescence time course for cells treated with TRPV1 antagonist BCTC (orange trace) or left untreated (green trace). The arrows indicate the time points chosen for determining the fluorescence ratio (see "Materials and methods" section). TRPV1-mediated $\mathrm{Ca}^{2+}$ influx was observed upon exposure to $50^{\circ} \mathrm{C}$ (green trace) while addition of BCTC $(300 \mathrm{nM})$ antagonized this response (orange trace). (C) Temperature time course. Note the correlation between high temperature in (C) and signal induction in non-BCTC-treated cells in panel $\mathrm{B}$.

temperature is used as the channel-opening modality (21). In the current study, we describe the use of a standard real-time PCR machine to develop a cell-based, functional assay employing temperature as an agonist for ion channel gating. We demonstrate this assay's potential for compound screening and its use in the analysis of small molecules targeting TRPV1. Furthermore, we subsequently describe the application of the assay to another temperature-sensitive TRP channel, the cold sensor TRPM8.

\section{Materials and methods}

\section{Reagents}

Tissue culture reagents, $5^{\prime}$-iodoresiniferatoxin (I-RTX), Fluo-4 AM, and capsazepine were

Table 1. Comparison of hTRPV1 potency data obtained in the temperature and other assays for known TRPV1 antagonists

\begin{tabular}{|c|c|c|c|}
\hline Antagonist & $\begin{array}{l}\text { Temperature assay } \\
\text { IC }_{50}, \mathrm{nM} \text { (sEM)a }\end{array}$ & $\begin{array}{l}\text { Electrophysiology } \\
\qquad \mathrm{IC}_{50}, \mathrm{nM}^{\mathrm{b}}\end{array}$ & $\begin{array}{c}\text { 3H-RTX binding assay } \\
\mathrm{K}_{\mathrm{i}}, \mathrm{nM} \text { (SEM)c }\end{array}$ \\
\hline ВCTC & $5.37(1.13)$ & 4.40 & $6.18(1.48)$ \\
\hline I-RTX & $6.06(0.31)$ & ND & $7.97(0.87)$ \\
\hline SB-705498 & $44(4)$ & 357 & $95.9(8.3)$ \\
\hline AMG-9810 & $129(0)$ & 113 & $91.3(16.9)$ \\
\hline SB-366791 & $304(58)$ & 956 & $>2000$ \\
\hline Capsazepine & $3100(1100)$ & ND & $1813(402)$ \\
\hline \multicolumn{4}{|c|}{$\begin{array}{l}\text { aMean of 2-3 independent experiments. bSingle determination against } 250 \mathrm{nM} \text { capsaicin. cMean of } 3-6 \\
\text { independent experiments. ND, not determined. }\end{array}$} \\
\hline
\end{tabular}

purchased from Mediatech (Manassas, VA, USA), Tocris-Cookson (Ellisville, MO, USA), Invitrogen (Carlsbad, CA, USA), and Sigma-Aldrich (St. Louis, MO, USA), respectively. Other chemical compounds were synthesized in-house.

\section{Constructs and cell culture}

The TRPV1 coding domain was amplified fromahuman DRGcDNA library (Clontech, Palo Alto, CA, USA) and the TRPM8 coding domain sequence was amplified from the Megaman human transcriptome library (Stratagene, La Jolla, CA, USA). Full-length coding domain sequences were ligated into pcDNA5TO and transfected into 293-TREx cells to generate stable TRPV1 or TRPM8expressing cell lines. Cells were cultured in DMEM, supplemented with $10 \%$ fetal bovine serum (Hyclone, Logan, UT, USA), 100 U/ $\mathrm{mL}$ penicillin, $100 \mu \mathrm{g} / \mathrm{mL}$ streptomycin, 200 $\mu \mathrm{M}$ glutamax, $5 \mu \mathrm{g} / \mathrm{mL}$ blasticidin and 200 $\mu \mathrm{g} / \mathrm{mL}$ hygromycin. TRPV1 (or TRPM8) expression was induced by adding $1 \mu \mathrm{g} / \mathrm{mL}$ doxycycline to the cell medium $24 \mathrm{~h}$ prior to the assay.

\section{Experimental protocols}

Cell preparation. Media was removed from the attached hTRPV1- (or hTRPM8-) expressing cells and a 1- $\mu \mathrm{M}$ Fluo- $4 \mathrm{AM}$ dye solution in PBS was applied for $30 \mathrm{~min}$ at $37^{\circ} \mathrm{C}$. Cells were then detached from the tissue culture dish using EDTA, centrifuged, resuspended in PBS, counted with a hemacytometer (Model no. 1483, Hausser Scientific, Horsham, PA, USA), and plated at 100,000 cells/well in a 96-well conical bottom PCR plate (Model no. EK-19280, Greiner, Monroe, NC, USA). Temperature control over the cellular environment was accomplished with an ABI 7700 instrument (Applied Biosystems, Foster City, CA, USA).

Temperature response curves. Cells were plated and assayed one column at a time as follows: for TRPV $1,22^{\circ} \mathrm{C}$ for $2 \mathrm{~min}$ followed by a temperature of between $36^{\circ} \mathrm{C}$ and $54^{\circ} \mathrm{C}$, in $2^{\circ} \mathrm{C}$ increments, for $5 \mathrm{~min}$; for TRPM8, $37^{\circ} \mathrm{C}$ for $2 \mathrm{~min}$ followed by a temperature between $37^{\circ} \mathrm{C}$ and $10^{\circ} \mathrm{C}$, in $3^{\circ} \mathrm{C}$ decrements, for $5 \mathrm{~min}$. While no significant fluorescence was observed in heated HEK293-TREx cells, some was observed when cells were cooled to $\leq 10^{\circ} \mathrm{C}$. Accordingly, background signal was subtracted for TRPM8-expressing cells prior to data analysis.

$Z^{\prime}$ factor and $\mathrm{IC}_{50}$ experiments. Antagonists were added to cells following the dye loading and cell plating steps. The following programs were applied to the assay plate: $22^{\circ} \mathrm{C}$ for $2 \mathrm{~min}$ followed by $50^{\circ} \mathrm{C}$ for $5 \mathrm{~min}$ (for TRPV1) or $37^{\circ} \mathrm{C}$ for $2 \mathrm{~min}$ followed by $14^{\circ} \mathrm{C}$ for $5 \mathrm{~min}$ (for TRPM8), with fluorescence data collected throughout.

\section{Data analysis}

Raw results were exported to Excel for the extraction of the fluorescence data collected at the starting and ending temperatures, which were used to calculate a fluorescence ratio. $\mathrm{IC}_{50}$ (half maximal concentration) and $\mathrm{T}_{50}$ (temperature at which half maximal signal is observed) curves were generated by fitting the fluorescence ratio data with a 4-parameter sigmoidal curve equation using GraphPad Prism (GraphPad Software, La Jolla, CA, USA):

$$
y=\text { bottom }+\frac{(\text { top }+ \text { bottom })}{1-10^{\left[\left(\log \mathrm{EC}_{50}-x\right) * n_{H}\right]}},
$$

[Eq. 1]

where $\mathrm{EC}_{50}$ is the concentration of agonist eliciting a response halfway between the baseline (bottom) and maximum response (top), $n_{H}$ is the Hill slope and $x=\log$ (concentration or temperature). Z'-factor and assay window (AW) determination were performed using the following equations:

$$
\mathrm{Z}^{\prime}=1-\frac{3 *\left(\mathrm{SD}_{\max }+\mathrm{sD}_{\min }\right)}{\mathrm{Mean}_{\text {max }}-\mathrm{Mean}_{\text {min }}}
$$

[Eq. 2] 


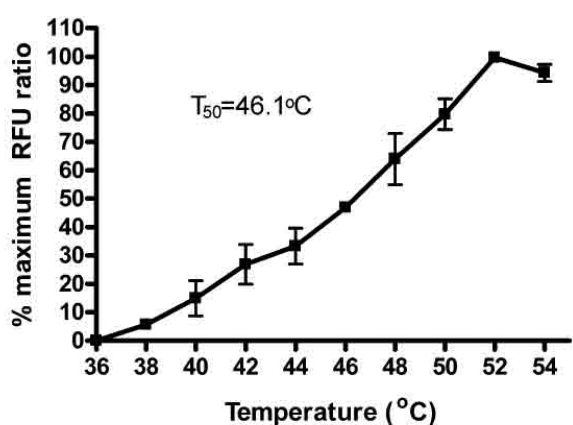

B

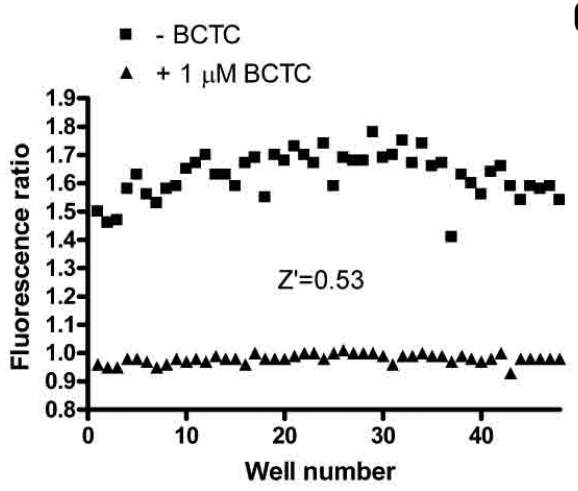

C

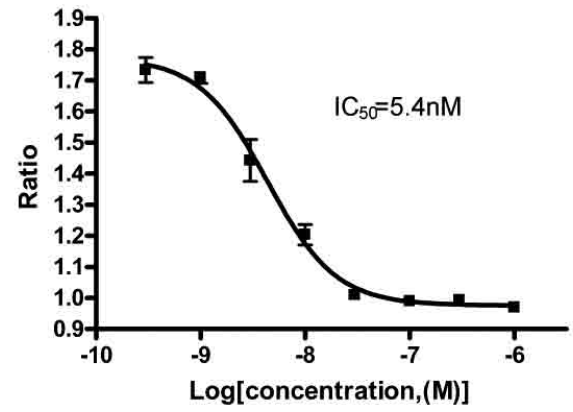

Figure 2. Assay characterization. (A) Temperature response curve for hTRPV1. TREx-hTRPV1 cells were exposed to a temperature curve (increasing in increments of $2^{\circ} \mathrm{C}$ ) and fluorescence ratios were calculated for each temperature. The temperature at which half of the hTRPV1 response is observed is $T_{50}=46.1^{\circ} \mathrm{C}\left(95 \%\right.$ confidence interval: $\left.44.6-47.6^{\circ} \mathrm{C}\right)$. This experiment was performed independently three times and the results were combined for analysis. Normalization was applied in order to control for ratio fluctuations between experiments and was calculated by dividing the ratio from each temperature by the maximal ratio (in this case, obtained at $52^{\circ} \mathrm{C}$ ) for that experiment. (B) Assay robustness as determined via $Z^{\prime}$ factor analysis. hTRPV1-expressing cells were plated in a 96-well format. In a checkerboard fashion, buffer or a buffer with BCTC were added in alternating wells. Three independent experiments were performed for this Z' factor determination and representative results are shown. (C) IC 50 Curve of TRPV1 antagonist BCTC. An IC 50 curve was obtained for BCTC in TREx-hTRPV1 cells using a stimulation temperature of $50^{\circ} \mathrm{C}$. The $I C_{50}$ value obtained for BCTC is $5.4 \mathrm{nM}$ (mean of three independent experiments) and a representative curve is shown (mean $\pm \mathrm{SEM}, n=8$ ).

$\mathrm{AW}=\left(\mathrm{Mean}_{\max }-\mathrm{Mean}_{\min }\right)-3\left(\mathrm{SD}_{\max }-\mathrm{SD}_{\min }\right)$.

Error bars in figures indicate standard error of the mean (SEM).

\section{Results and discussion}

Experimental setup and signal detection

A common readout for ion channel functional activity is the fluorescence observed in the presence of binding between incoming ions and an intracellular dye whose fluorescence properties are modified through binding to these ions. As a standard real-time PCR machine provides both a fluorescence excitation and reading capability along with tight temperature control, we postulated it could be used to monitor the functional activity of temperature-sensitive ion channels in live cells. An additional benefit lay in the 96-well format found in our real-time PCR machine of choice (ABI 7700), which suggested the possible simultaneous analysis of multiple sets of conditions. However, specific constraints were encountered in adapting the ABI 7700 from DNA analysis into a cell-based temperature assay platform in order to exploit its tight temperature regulation: in particular, single line excitation with the laser of this instrument at $488 \mathrm{~nm}$ excluded the possible use of ratiometric dyes such as Fura-2 or Indo-1, which are most commonly used to assess $\mathrm{Ca}^{2+}$ influx. As the $\mathrm{Ca}^{2+}$-sensitive dye Fluo-4 possesses similar excitation/emission (ex/em) characteristics compared with FITC (ex $491 \mathrm{~nm} / \mathrm{em} 516 \mathrm{~nm}$ and ex $488 \mathrm{~nm} / \mathrm{em} 518 \mathrm{~nm}$, respectively), a dye commonly used for real-time PCR reactions, the ABI 7700 instrument was capable of detecting changes in Fluo-4 fluorescence induced by its binding to calcium ions (Figure 1A). Thus, hTRPV1-expressing cells in suspension were preloaded with Fluo-4, placed in a 96 well Taqman assay plate, and loaded into the ABI7700 where their temperature was modulated at a rate of up to $1{ }^{\circ} \mathrm{C} / \mathrm{s}$. As shown in Figure $1 \mathrm{~B}$, heatinduced $\mathrm{Ca}^{2+}$ influx through the TRPV1 channel can be observed as an increase in fluorescence (green trace) concomitant with the rapid, yet precisely controlled rise in temperature from $22^{\circ} \mathrm{C}$ to $50^{\circ} \mathrm{C}$ (Figure 1C). Importantly, $\mathrm{Ca}^{2+}$ influx was only observed in TREx-hTRPV1 cells and not in untransfected TREx cells (data not shown). This signal represents a homogeneous readout of cells in suspension and can be blocked by the addition of $\mathrm{N}$-(4-tertiarybutylphenyl)4-(3-chloropyridin-2-yl)tetrahydropyrazine- $1(2 \mathrm{H})$-carbox-amide (BCTC; Figure 1B, orange trace), a known TRPV1 antagonist (22). For reasons that are not clear, the initial increase in temperature leads to a transient decrease in fluorescence (Figure 1B). This dip in signal is not TRPV1-dependent since it is also observed in untransfected TREx cells (data not shown).
Temperature response curve of TRPV1 In order to get a more detailed understanding of the relationship between temperature and TRPV1 activation, hTRPV1-expressing cells were exposed to a range of increasing temperatures (Figure 2A). A temperature response curve was obtained with a $\mathrm{T}_{50}$ value of $46.1^{\circ} \mathrm{C}$, the temperature at which $50 \%$ of the maximum signal was observed. Maximal channel activity was recorded at $52^{\circ} \mathrm{C}$ with no further fluorescence increases above this temperature, suggesting that all the cells present in the well were fully activated at this point. It should be noted that based on the characteristics of the dye $\left[\mathrm{Ca}^{2+}\right.$-Fluo-4 dissociation constant $\left(K_{D}\right)=345 \mathrm{nM}$ ], the signal can be expected to be approximately linear between $\sim 35 \mathrm{nM}$ and $\sim 3.5 \mu \mathrm{M}$, and will start to saturate at higher intracellular concentrations of calcium. Importantly, as TRPV1 can be sensitized by previous activation (including exposure to heat), each data point was obtained from a naive set of cells not previously heated. These results are not only consistent with published electrophysiology data indicating channel opening at $42-45^{\circ} \mathrm{C}$, but they also delineate the maximal excitation of the temperature response of TRPV1 (12). Furthermore, as a cell population is being studied instead of a single cell, some signal is observed below and above the normal temperature threshold of $42^{\circ} \mathrm{C}$ as documented previously by others (23). The use of a cell population also explains why the temperature dependency of channel opening $\left(\mathrm{Q}_{10}\right)$ observed in this experiment is lower than in singlecell experiments: the activity of all the cells is integrated, including those with a lower- 

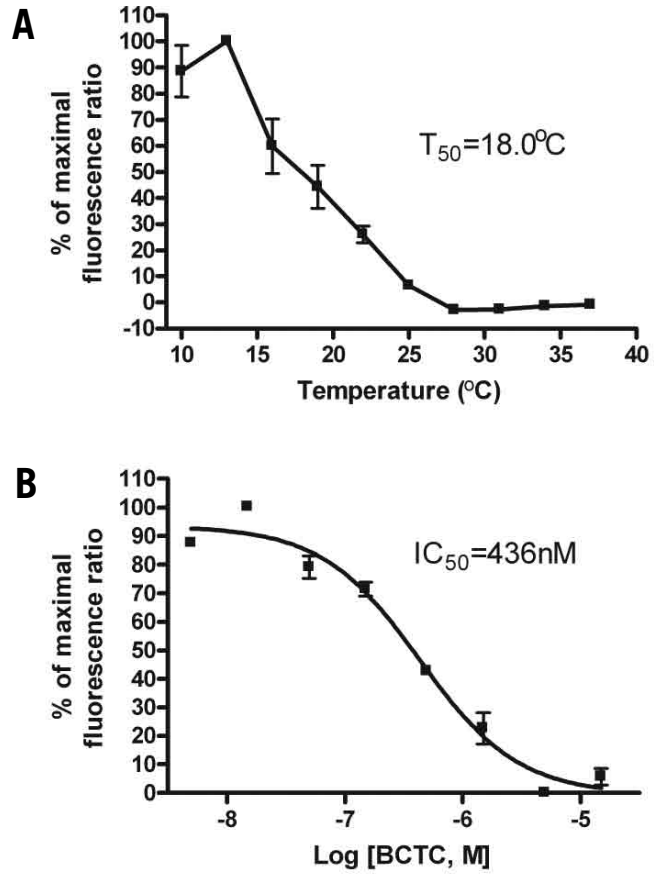

Figure 3. Cold-gated $\mathrm{Ca}^{2+}$ influx in hTRPM8-expressing cells. (A) Temperature response curve for hTRPM8-mediated $\mathrm{Ca}^{2+}$ influx. TREx-hTRPM8 cells were exposed to a temperature curve (decreasing in increments of $3^{\circ} \mathrm{C}$ ) and fluorescence ratios were calculated for each temperature. This experiment was performed independently twice and the results were combined for analysis. Normalization was applied in order to control for ratio fluctuations between experiments and was calculated by dividing the ratio from each temperature by the maximal ratio (in this case, obtained at $13^{\circ} \mathrm{C}$ ) for that experiment. The temperature at which half of the hTRPM 8 response is observed is $T_{50}=18.0^{\circ} \mathrm{C}\left(95 \%\right.$ confidence interval: $\left.17.1-18.9^{\circ} \mathrm{C}\right)$. (B) $\mathrm{An} \mathrm{IC}_{50}$ curve was obtained for $\mathrm{BCTC}$ in TREx-hTRPM8 cells using a stimulation temperature of $14^{\circ} \mathrm{C}$. The average $I \mathrm{C}_{50}$ value obtained for BCTC is $436 \mathrm{nM}$ (95\% confidence interval: 274-695 nM). This experiment was performed independently twice and the results were combined for analysis (mean \pm SEM, $n=2$ ).

and higher-than-average threshold, and this integration will result in a shallower response curve.

\section{Assay characterization}

In order to validate this assay for screening purposes, the statistical parameters of the assay data were evaluated in 96-well format using BCTC as a positive control. As can be seen in Figure 2B, this temperature assay displayed a $Z^{\prime}$ factor of 0.53 , above the generally accepted threshold of 0.5 value indicating that an assay is suitable for high throughput screening (24). Additionally, the assay window was calculated to be 0.38 fluorescence ratio units.

\section{IC $_{50}$ determination for known TRPV1 antagonists}

The inhibition of capsaicin- and low pH-activated TRPV1 by BCTC has been well characterized (22). We used this temperature assay to determine its potency against heat-activated hTRPV1. Our experimental data indicates that BCTC is a potent inhibitor of heat-activated hTRPV1 calcium influx as well (Figure $\left.2 \mathrm{C}, \mathrm{IC}_{50}=5.4 \mathrm{nM}\right)$. Potency values in the temperature assay for other published TRPV1 antagonists can be seen in Table 1 . All antagonists tested were capable of inhibiting heat activation of TRPV1. However, we, like others (25), found SB-366791 to appear less potent than originally predicted (26) and capsazepine displayed a relatively high $\mathrm{IC}_{50}$ as well. Interestingly, the ranking order of these compounds is mostly conserved in the three widely different assays chosen for comparison: calcium influx with heat activation, electrophysiology with capsaicin stimulation, and binding with $\left[{ }^{3} \mathrm{H}\right]$-Resiniferatoxin $\left(\left[{ }^{3} \mathrm{H}\right]\right.$ RTX) displacement. These results are consistent with the hypothesis that heat activation of TRPV1 is susceptible to the same inhibitory molecular mechanisms to which other agonist modalities are sensitive.

\section{Application of the temperature assay to cold-sensing TRPM8}

In addition to TRPV1, the activation of multiple other TRP channels (TRPV2, TRPV3, TRPV4, TRPA1, and TRPM8) has been shown to be temperaturedependent. Gating by temperature across

\section{BioTechnioues}

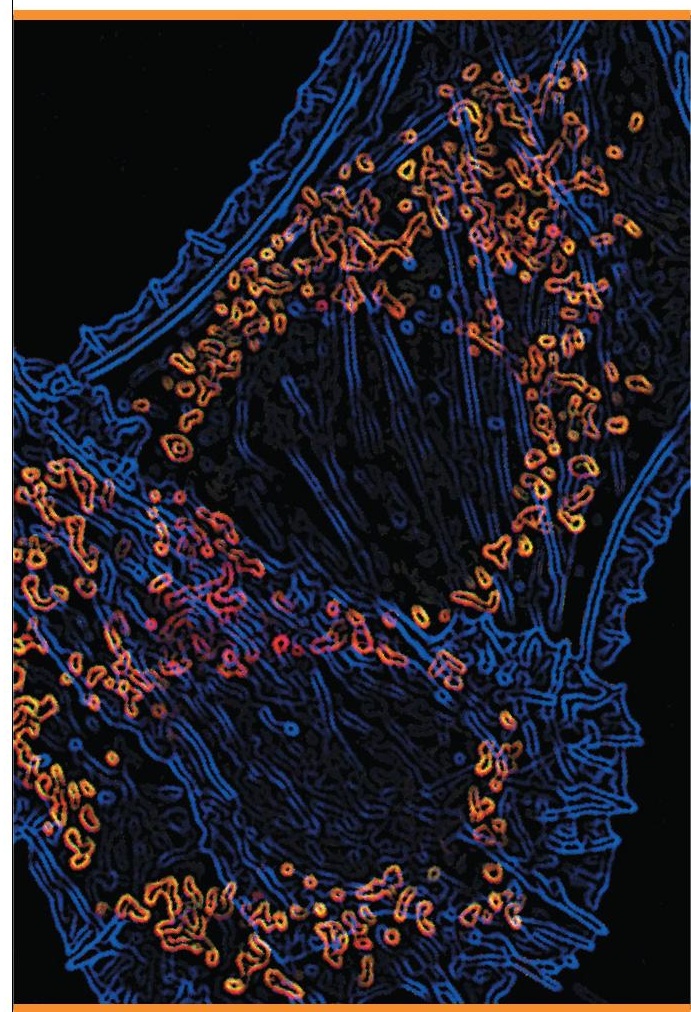

\section{BioTechniques}

\section{E-Alerts}

\section{BioTechniques Weekly}

Weekly newsletter with industry insight for life scientists: news, new products, grants deadlines, employment opportunities, and events.

\section{Advance Online Publication (AOP)}

Monthly alert with select research papers published online ahead of the print.

\section{Table of Contents (TOC)}

Monthly alert listing current papers and their links allowing you to browse the latest issue immediately.

Register today at www.BioTechniques.com/newsletters

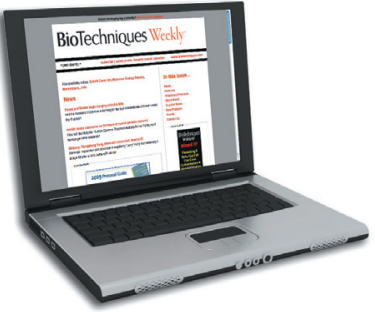


a broad thermal spectrum can be seen for TRP family members as both heat (e.g., TRPV1) and cold (e.g., TRPM8) can lead to channel opening. Accordingly, we applied this temperature assay to coldactivated TRPM8 to assess the utility of this assay platform for studying and screening against cold-sensing channels. A protocol similar to that followed in TRPV1 experiments was utilized with the exception that TRPM8 cells were initially held at $37^{\circ} \mathrm{C}$ before their temperature was subsequently lowered to sub-physiological levels. As shown previously with TRPV1, a temperature response curve depicting the activation of TRPM8 as a function of decreasing temperatures could be obtained (Figure $3 \mathrm{~A}$ ) with a $\mathrm{T}_{50}$ of $18.0^{\circ} \mathrm{C}$, consistent with the thresholds reported for TRPM8 activation using electrophysiology in mammalian cells heterologously expressing TRPM8 (6,7). Each data point was obtained from an independent set of naive cells that were not previously cooled. The TRPV1 antagonist BCTC is also an antagonist of menthol-activated TRPM8, albeit at much higher concentrations (27). Application of BCTC to cold-activated TRPM8 expressing cells prevented $\mathrm{Ca}^{2+}$ influx at high concentrations $(10 \mu \mathrm{M})$ and its $\mathrm{IC}_{50}$ was determined to be $436 \mathrm{nM}$ (Figure 3B), a result consistent with the values obtained against menthol-activated TRPM8 in-house $\left[\mathrm{IC}_{50}=438 \mathrm{nM}(95 \%\right.$ confidence interval: 261-733 nM), data not shown] and reported previously by others using electrophysiology (27). These results illustrate that this technical approach is suitable for the study of the cold-activated ion channel TRPM8.

Under physiological conditions, temperature can act as an endogenous agonist for a variety of TRP ion channels. We have developed a temperature-based $\mathrm{Ca}^{2+}$ influx assay that can be used to study and screen for agents that alter the thermal response of these temperature-sensitive channels. Characterization of this assay for TRPV1, including a $Z^{\prime}$-factor of $>0.5$, demonstrates that it is amenable to screening within a drug discovery paradigm. For TRPV1 antagonists, data obtained using this assay produced $\mathrm{IC}_{50}$ trends similar to those observed in other well established TRPV1 assays.

The effect of temperature on channel activity has previously been assessed using electrophysiology and we propose this technique as a complementary approach for the use of temperature as an activation mechanism. The features differentiating it from electrophysiology include a 96-well format, the ability to study cell populations instead of single cells, and the use of equipment and personnel skills already present in most biology laboratories. Similarly, a radioactive ${ }^{45} \mathrm{Ca}^{2+}$ influx assay-where TRPV1-expressing cells were placed in a $45^{\circ} \mathrm{C}$ water bath-was published recently and can be used to characterize select compounds (20). However, this approach does not provide the kinetic, real-time read of channel activity nor the thermo-temporal control over the cellular environment that the approach herein provides. Importantly, temperature acts as an activation mechanism for multiple other TRP family members, some of which do not have well characterized direct small-molecule agonists. The technique presented here may be useful in studies of these channels.

The potential importance of characterizing an antagonist's ability to inhibit heat gating of TRPV1 is exemplified by capsazepine. This TRPV1 antagonist inhibits capsaicin-activated rat TRPV1 completely, but displays only partial inhibition of heat-activated rTRPV1 and has no effect on activation by low $\mathrm{pH}$. This decoupling of inhibition toward different activation mechanisms was hypothesized to be responsible for the lack of efficacy observed in pain studies conducted in rats treated with capsazepine $(25,28)$. In these regards, a screening approach using temperature as the agonist may hold particular value in drug development. This study demonstrates the usefulness of this technique with both heat- (TRPV1) and cold-(TRPM8) activated ion channels for screening and characterization purposes.

\section{Acknowledgments}

We wish to thank Nina Orike, Alejandra Acevedo, David Hackos, Michelle Dourado, Joy Shen, and Joanne Kwan for their contributions to this study.

The authors declare no competing interests.

\section{References}

1. Rodriguez, B.M., D. Sigg, and F. Bezanilla. 1998. Voltage gating of Shaker K+ channels. The effect of temperature on ionic and gating currents. J. Gen. Physiol. 112:223-242.

2.Allen, T.J. and G. Mikala. 1998. Effects of temperature on human L-type cardiac $\mathrm{Ca} 2+$ channels expressed in Xenopus oocytes. Pflugers Arch. 436:238-247.

3. Pusch, M., U. Ludewig, and T.J. Jentsch. 1997. Temperature dependence of fast and slow gating relaxations of $\mathrm{ClC}-0$ chloride channels. J. Gen. Physiol. 109:105-116.

4.Voets, T., G. Droogmans, U. Wissenbach, A. Janssens, V. Flockerzi, and B. Nilius. 2004. The principle of temperaturedependent gating in cold- and heat-sensitive TRP channels. Nature 430:748-754.
5.Dhaka, A., V. Viswanath, and A. Patapoutian. 2006. Trp ion channels and temperature sensation. Annu. Rev. Neurosci. 29:135-161.

6.Peier, A.M., A. Moqrich, A.C. Hergarden, A.J. Reeve, D.A. Andersson, G.M. Story, T.J. Earley, I. Dragoni, et al. 2002. A TRP channel that senses cold stimuli and menthol. Cell 108:705-715.

7. McKemy, D.D., W.M. Neuhausser, and D. Julius. 2002. Identification of a cold receptor reveals a general role for TRP channels in thermosensation. Nature 416:52-58.

8.Story, G.M., A.M. Peier, A.J. Reeve, S.R. Eid, J. Mosbacher, T.R. Hricik, T.J. Earley, A.C. Hergarden, et al. 2003. ANKTM1, a TRP-like channel expressed in nociceptive neurons, is activated by cold temperatures. Cell 112:819-829.

9. Peier, A.M., A.J. Reeve, D.A. Andersson, A. Moqrich, T.J. Earley, A.C. Hergarden, G.M. Story, S. Colley, et al. 2002. A heat-sensitive TRP channel expressed in keratinocytes. Science 296:2046-2049.

10.Guler, A.D., H. Lee, T. Iida, I. Shimizu, M. Tominaga, and M. Caterina. 2002. Heat-evoked activation of the ion channel, TRPV4. J. Neurosci. 22:64086414 .

11.Caterina, M.J., T.A. Rosen, M. Tominaga, A.J. Brake, and D. Julius. 1999. A capsaicin-receptor homologue with a high threshold for noxious heat. Nature 398:436441.

12.Hayes, P., H.J. Meadows, M.J. Gunthorpe, M.H. Harries, D.M. Duckworth, W. Cairns, D.C. Harrison, C.E. Clarke, et al. 2000. Cloning and functional expression of a human orthologue of rat vanilloid receptor-1. Pain 88:205-215.

13. Talavera, K., K. Yasumatsu, T. Voets, G. Droogmans, N. Shigemura, Y. Ninomiya R.F. Margolskee, and B. Nilius. 2005. Heat activation of TRPM 5 underlies thermal sensitivity of sweet taste. Nature 438:1022-1025.

14.Szallasi, A., D.N. Cortright, C.A. Blum, and S.R. Eid. 2007. The vanilloid receptor TRPV1: 10 years from channel cloning to antagonist proof-of-concept. Nat. Rev. Drug Discov. 6:357-372.

15. Olah, Z., L. Karai, and M.J. Iadarola. 2001. Anandamide activates vanilloid receptor 1 (VR1) at acidic $\mathrm{pH}$ in dorsal root ganglia neurons and cells ectopically expressing VR1. J. Biol. Chem. 276:31163-31170.

16. Tsavaler, L., M.H. Shapero, S. Morkowski, and R. Laus. 2001. Trp-p8, a novel prostate-specific gene, is up-regulated in prostate cancer and other malignancies and shares high homology with transient receptor potential calcium channel proteins. Cancer Res. 61:3760-3769.

17. Kobayashi, K., T. Fukuoka, K. Obata, H. Yamanaka, Y. Dai, A. Tokunaga, and K. Noguchi. 2005. Distinct expression of TRPM8, TRPA1, and TRPV1 mRNAs in rat primary afferent neurons with adelta/cfibers and colocalization with trk receptors. J. Comp. Neurol. 493:596-606.

18. Nilius, B. and T. Voets. 2007. Neurophysiology: channelling cold reception. Nature 448:147-148.

19. Bandell, M., A.E. Dubin, M.J. Petrus, A. Orth, J. Mathur, S.W. Hwang, and A. Patapoutian. 2006. High-throughput random 
mutagenesis screen reveals TRPM8 residues specifically required for activation by menthol. Nat. Neurosci. 9:493-500.

20.Gavva, N.R., R. Tamir, Y. Qu, L. Klionsky, T.J. Zhang, D. Immke, J. Wang, D. Zhu, et al. 2005. AMG 9810 [(E)-3-(4-tbutylphenyl)-N-(2,3-dihydrobenzo[b][1,4] dioxin-6-yl)acrylamide], a novel vanilloid receptor 1 (TRPV1) antagonist with antihyperalgesic properties. J. Pharmacol. Exp. Ther. 313:474-484.

21. Dittert, I., J. Benedikt, L. Vyklicky, K. Zimmermann, P.W. Reeh, and V. Vlachova. 2006. Improved superfusion technique for rapid cooling or heating of cultured cells under patch-clamp conditions. J. Neurosci. Methods 151:178-185.

22.Valenzano, K.J., E.R. Grant, G. Wu, M. Hachicha, L. Schmid, L. Tafesse, Q. Sun, Y. Rotshteyn, et al. 2003. N-(4-tertiarybutylphenyl)-4-(3chloropyridin-2-yl)tetrahydropyrazine $-1(2 \mathrm{H})$-carbox-amide (BCTC), a novel, orally effective vanilloid receptor 1 antagonist with analgesic properties: I. in vitro characterization and pharmacokinetic properties. J. Pharmacol. Exp. Ther. 306:377-386.

23. Savidge, J.R., S.P. Ranasinghe, and H.P. Rang. 2001. Comparison of intracellular calcium signals evoked by heat and capsaicin in cultured rat dorsal root ganglion neurons and in a cell line expressing the rat vanilloid receptor, VR1. Neuroscience 102:177-184.

24.Zhang, J.H., T.D. Chung, and K.R. Oldenburg. 1999. A simple statistical parameter for use in evaluation and validation of high throughput screening assays. J. Biomol. Screen. 4:67-73.

25. Gavva, N.R., R. Tamir, L. Klionsky, M.H. Norman, J.C. Louis, K.D. Wild, and J.J. Treanor. 2005. Proton activation does not alter antagonist interaction with the capsaicinbinding pocket of TRPV1. Mol. Pharmacol. 68:1524-1533.

26.Gunthorpe, M.J., H.K. Rami, J.C. Jerman, D. Smart, C.H. Gill, E.M. Soffin, S. Luis Hannan, S.C. Lappin, et al. 2004. Identification and characterisation of SB-366791, a potent and selective vanilloid receptor (VR1/ TRPV1) antagonist. Neuropharmacology 46:133-149.

27. Weil, A., S.E. Moore, N.J. Waite, A. Randall, and M.J. Gunthorpe. 2005. Conservation of functional and pharmacological properties in the distantly related temperature sensors TRVP1 and TRPM8. Mol. Pharmacol. 68:518-527.

28. McIntyre, P., L.M. McLatchie, A. Chambers, E. Phillips, M. Clarke, J. Savidge, C. Toms, M. Peacock, et al. 2001. Pharmacological differences between the human and rat vanilloid receptor 1 (VR1). Br. J. Pharmacol. 132:1084-1094.

Received 9 October 2007; accepted 5 May 2009.

Address correspondence to Fabien Vincent, Ph.D., Evotec, Two Corporate Drive, South San Francisco, CA, 94080, USA. email: fabien vincent_us@yahoo.com

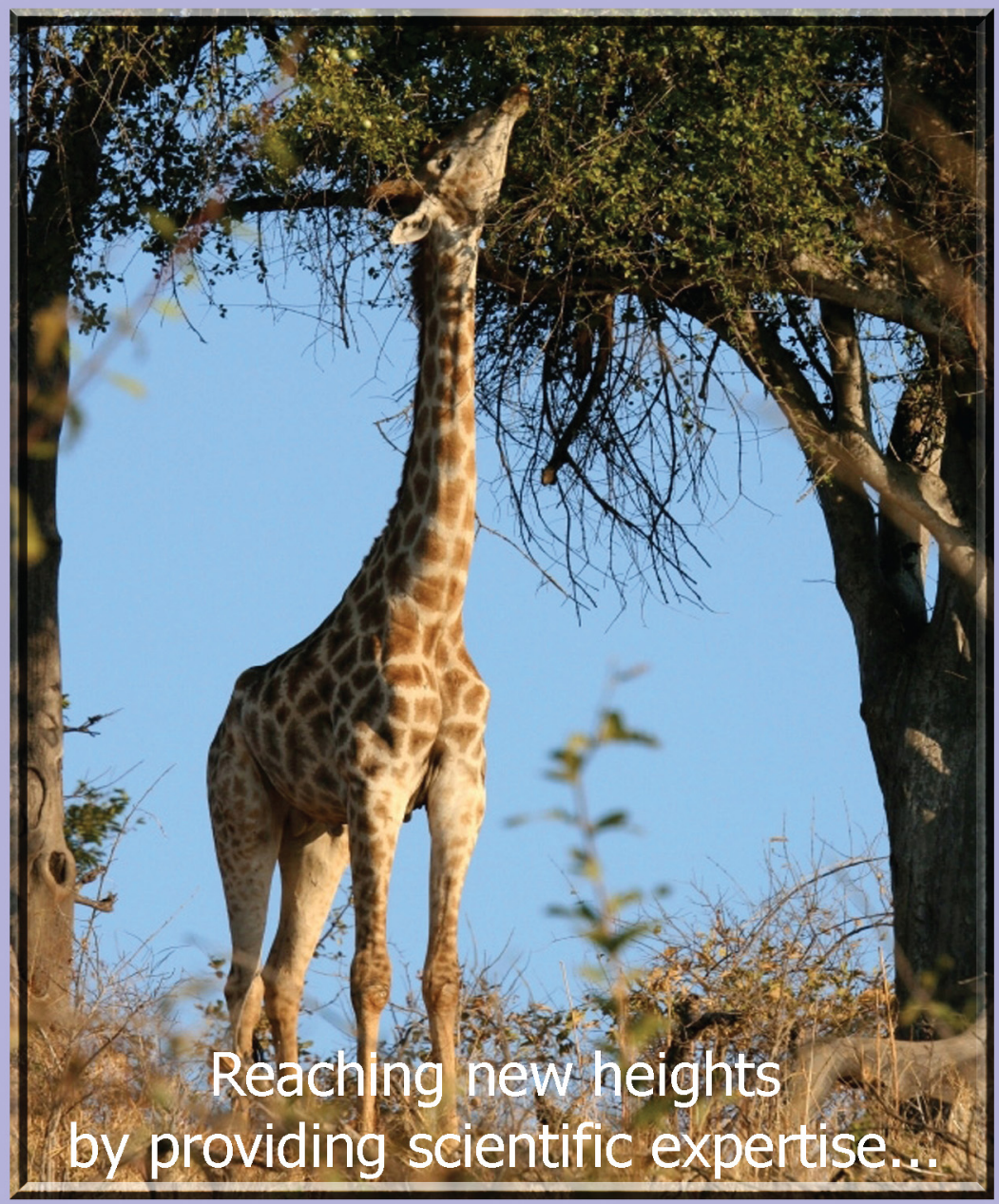

Assay Development

- Nucleic Acid Purification

Genotyping

- Microarray Technology

qRT-PCR

- Bioinformatics

Tumor Profiling

Sample Management

- Biostorage

Consulting

\section{THE Pharmacogenomics Company}

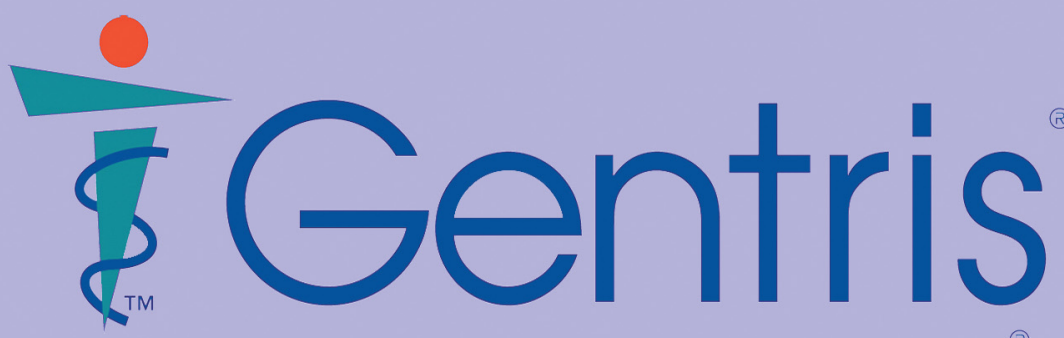

Revolutionizing Medicine Through Pharmacogenomics 